\title{
Evaluation of anthropometric parameters and physical fitness in elderly Japanese
}

\author{
Nobuyuki Miyatake $\cdot$ Motohiko Miyachi $\cdot$ \\ Izumi Tabata $\cdot$ Takeyuki Numata
}

Received: 1 April 2011/Accepted: 27 April 2011/Published online: 19 May 2011

(C) The Japanese Society for Hygiene 2011

\begin{abstract}
Objectives We evaluated anthropometric parameters and physical fitness in elderly Japanese.

Methods A total of 2,106 elderly Japanese (749 men and 1,357 women), aged 60-79 years, were enrolled in a crosssectional investigation study. Anthropometric parameters and physical fitness, i.e., muscle strength and flexibility, were measured. Of the 2,106 subjects, 569 subjects (302 men and 267 women) were further evaluated for aerobic exercise level, using the ventilatory threshold (VT).

Results Muscle strength in subjects in their 70s was significantly lower than that in subjects in their $60 \mathrm{~s}$ in both sexes. Two hundred and twenty-nine men (30.6\%) and 540 women $(39.8 \%)$ were taking no medications. In men, anthropometric parameters were significantly lower and muscle strength, flexibility, and work rate at VT were significantly higher in subjects without medications than these values in subjects with medications. In women, body
\end{abstract}

N. Miyatake $(\square)$

Department of Hygiene, Faculty of Medicine,

Kagawa University, Miki, Kagawa 761-0793, Japan

e-mail: miyarin@med.kagawa-u.ac.jp

M. Miyachi

National Institute of Health and Nutrition,

Tokyo 162-8636, Japan

I. Tabata

Sports and Health Science, Ritsumeikan University,

Kusatsu, Shiga 525-8577, Japan

T. Numata

Okayama Southern Institute of Health,

Okayama Health Foundation, Okayama 700-0952, Japan weight, body mass index (BMI), and abdominal circumference were significantly lower, and muscle strength was significantly higher in subjects without medications than these values in subjects with medications.

Conclusion This mean value may provide a useful database for evaluating anthropometric parameters and physical fitness in elderly Japanese subjects.

Keywords Elderly Japanese · Anthropometric parameters - Muscle strength · Ventilatory threshold (VT)

\section{Introduction}

The proportion of elderly people (over the age of 65 years) in Japan has increased and this has become a public health challenge in Japan. For example, in Japan, 28,216,000 people $(22.1 \%$ of the population) are reported to be over the age of 65 [1].

It has been shown that obese subjects have a high mortality rate [2] and have associated atherogenic risk factors, such as hypertension, coronary heart disease, diabetes mellitus, and dyslipidemia [3, 4]. In addition, Sandvik et al. reported that physical fitness was a graded, independent, long-term predictor of mortality from cardiovascular causes in healthy, middle-aged men [5]. Also, Metter et al. [6] reported that lower and declining muscle strength was associated with increased mortality, independent of physical activity and muscle mass. In order to provide proper management and control of anthropometric parameters and physical fitness in elderly Japanese, precise assessments of these parameters are necessary. However, the evaluation of anthropometric parameters and physical fitness still remains to be investigated in elderly Japanese who are not taking medications. 
Therefore, we evaluated anthropometric parameters and physical fitness in elderly Japanese and compared these parameters in subjects with and without medications.

\section{Subjects and methods}

\section{Subjects}

We used data for all 2,106 elderly subjects (749 men and 1,357 women), aged 60-79 years, among 16,383 subjects in a cross-sectional investigation study. All subjects met the following criteria: (1) they had been wanting to change their lifestyle i.e., diet and exercise habits, and had received an annual health checkup between June 1997 and December 2009 at Okayama Southern Institute of Health; (2) their anthropometric, muscle strength, and flexibility measurements had been taken as part of their annual health checkups; and (3) they provided written informed consent (Table 1).

In a second analysis, among the 2,106 subjects, we further examined the data on 569 subjects (302 men and 267 women) who undertook measurements of aerobic exercise level; we also examined anthropometric, muscle strength, and flexibility measurements in these secondanalysis subjects (Table 2).

The study was approved by the Ethics Committee of Okayama Health Foundation.

\section{Athropometric measurements}

The anthropometric parameters were evaluated by using the following parameters: height, body weight, body mass index (BMI), abdominal circumference, and hip circumference. BMI was calculated as weight/[height $]^{2}\left(\mathrm{~kg} / \mathrm{m}^{2}\right)$.
The abdominal circumference was measured at the umbilical level and the hip was measured at the widest circumference over the trochanter in standing subjects after normal expiration [7].

Muscle strength

To assess muscle strength, grip and leg strength were measured. Grip strength was measured using the THP-10 (SAKAI, Tokyo, Japan) device, while leg strength was measured with a dynamometer (COMBIT CB-1; MINATO Co., Osaka, Japan). Isometric leg strength was measured as follows: the subject sat in a chair, grasping the armrest in order to fix the body position. The dynamometer was then attached to the subject's ankle joint with a strap. Next, the subject extended the leg to $60^{\circ}$ [8]. To standardize the influence of the total body weight, we calculated the muscle strength $(\mathrm{kg})$ per body weight $(\mathrm{kg})$ [9].

\section{Flexibility}

Flexibility was measured as follows in all the participants. Sit-and-reach measurements were obtained to assess the overall flexibility in forward flexion, with the measurements recorded as the distance (in $\mathrm{cm}$ ) between the fingertips and toes. The subject's knees were kept straight throughout the test and ankles were maintained at $90^{\circ}$ by having the soles of the feet pressed against a board perpendicular to the sitting surface [10].

Oxygen uptake at ventilatory threshold (VT)

A graded ergometer exercise protocol [11] had been carried out at the subjects' checkups. After breakfast (2 h), resting

Table 1 Clinical profiles of subjects enrolled in the first analysis

\begin{tabular}{|c|c|c|c|c|c|c|}
\hline & \multicolumn{3}{|l|}{$\operatorname{Men}(n=749)$} & \multicolumn{3}{|c|}{ Women $(n=1,357)$} \\
\hline & Mean $\pm \mathrm{SD}$ & Minimum & Maximum & Mean \pm SD & Minimum & Maximum \\
\hline Age (years) & $65.6 \pm 4.6$ & 60 & 79 & $64.9 \pm 4.2$ & 60 & 79 \\
\hline Height (cm) & $164.4 \pm 5.5$ & 145.3 & 180.2 & $151.9 \pm 5.0$ & 136.2 & 167.0 \\
\hline Body weight (kg) & $65.9 \pm 9.3$ & 40.1 & 112.2 & $55.3 \pm 7.9$ & 33.4 & 97.3 \\
\hline Body mass index $\left(\mathrm{kg} / \mathrm{m}^{2}\right)$ & $24.3 \pm 3.0$ & 16.2 & 40.9 & $24.0 \pm 3.2$ & 15.4 & 41.9 \\
\hline Abdominal circumference $(\mathrm{cm})$ & $86.1 \pm 9.2$ & 61.6 & 127.0 & $78.8 \pm 9.3$ & 54.7 & 121.6 \\
\hline Hip circumference $(\mathrm{cm})$ & $91.9 \pm 5.5$ & 77.8 & 122.7 & $90.3 \pm 5.4$ & 69.0 & 120.5 \\
\hline Right grip strength (kg) & $36.4 \pm 7.0$ & 8.7 & 60.0 & $22.3 \pm 4.6$ & 4.9 & 39.9 \\
\hline Left grip strength (kg) & $35.0 \pm 6.9$ & 5.0 & 55.7 & $21.4 \pm 4.5$ & 4.3 & 47.4 \\
\hline Leg strength $(\mathrm{kg})$ & $51.0 \pm 13.4$ & 11.7 & 97.0 & $35.3 \pm 8.6$ & 10.7 & 69.7 \\
\hline Leg strength per body weight & $0.78 \pm 0.19$ & 0.20 & 1.50 & $0.65 \pm 0.17$ & 0.15 & 1.26 \\
\hline Flexibility $(\mathrm{cm})$ & $0.6 \pm 10.3$ & -34.0 & 28.3 & $11.2 \pm 8.1$ & -22.0 & 28.4 \\
\hline Number of subjects without medications (\%) & $229(30.6)$ & & & $540(39.8)$ & & \\
\hline
\end{tabular}


Table 2 Clinical profiles of subjects enrolled in the second analysis

\begin{tabular}{|c|c|c|c|c|c|c|}
\hline & \multicolumn{3}{|l|}{ Men $(n=302)$} & \multicolumn{3}{|c|}{ Women $(n=267)$} \\
\hline & Mean $\pm \mathrm{SD}$ & Minimum & Maximum & Mean \pm SD & Minimum & Maximum \\
\hline Age (years) & $65.3 \pm 4.3$ & 60 & 79 & $64.7 \pm 4.0$ & 60 & 77 \\
\hline Height $(\mathrm{cm})$ & $164.6 \pm 5.1$ & 149.1 & 178.3 & $152.4 \pm 4.2$ & 142.2 & 164.2 \\
\hline Body weight (kg) & $68.6 \pm 9.7$ & 47.6 & 112.2 & $59.3 \pm 8.8$ & 37.6 & 97.3 \\
\hline Body mass index $\left(\mathrm{kg} / \mathrm{m}^{2}\right)$ & $25.3 \pm 3.1$ & 18.9 & 40.9 & $25.5 \pm 3.7$ & 16.7 & 41.9 \\
\hline Abdominal circumference $(\mathrm{cm})$ & $88.8 \pm 9.8$ & 62.5 & 127.0 & $83.4 \pm 10.6$ & 60.0 & 121.6 \\
\hline Hip circumference $(\mathrm{cm})$ & $93.2 \pm 6.0$ & 79.7 & 122.7 & $92.4 \pm 6.4$ & 72.5 & 120.5 \\
\hline Right grip strength (kg) & $36.3 \pm 6.8$ & 13.4 & 60.0 & $22.1 \pm 4.7$ & 6.6 & 34.9 \\
\hline Left grip strength $(\mathrm{kg})$ & $35.1 \pm 6.4$ & 15.6 & 54.1 & $21.2 \pm 4.5$ & 6.9 & 33.0 \\
\hline Leg strength $(\mathrm{kg})$ & $51.0 \pm 13.1$ & 19.0 & 92.0 & $35.2 \pm 9.0$ & 11.0 & 69.7 \\
\hline Leg strength per body weight & $0.75 \pm 0.19$ & 0.26 & 1.17 & $0.60 \pm 0.15$ & 0.16 & 1.08 \\
\hline Flexibility (cm) & $-0.9 \pm 10.1$ & -34.0 & 23.7 & $9.7 \pm 8.3$ & -22.0 & 26.4 \\
\hline Oxygen uptake at VT $(\mathrm{ml} / \mathrm{kg} / \mathrm{min})$ & $12.5 \pm 2.0$ & 5.9 & 21.6 & $11.9 \pm 1.7$ & 7.6 & 16.8 \\
\hline Work rate at VT (watt) & $53.6 \pm 13.8$ & 5.0 & 100.0 & $38.7 \pm 10.5$ & 5.0 & 70.0 \\
\hline Heart rate at VT (beats/min) & $95.7 \pm 12.9$ & 64.0 & 146.0 & $99.0 \pm 12.8$ & 67.0 & 137.0 \\
\hline Number of subjects without medications (\%) & $33(10.9)$ & & & $55(20.6)$ & & \\
\hline
\end{tabular}

$V T$ ventilatory threshold

ECG was recorded and blood pressure was measured. All subjects were then given a graded exercise after 3 min of pedaling on an unloaded bicycle ergometer (Excalibur V2.0; Lode, Groningen, The Netherlands). The profile of incremental workloads was automatically defined by the methods of Jones et al. [11], in which the workloads reach the predicted maximum rate of oxygen consumption $\left(\dot{V} \mathrm{O}_{2 \max }\right)$ in $10 \mathrm{~min}$. A pedaling cycle of $60 \mathrm{rpm}$ was maintained. Loading was terminated when the appearance of symptoms forced the subject to stop. During the test, ECG was monitored continuously, together with recording of the heart rate. Expired gas was collected, and rates of oxygen consumption $\left(\dot{V} \mathrm{O}_{2}\right)$ and carbon dioxide production $\left(\dot{V} \mathrm{CO}_{2}\right)$ were measured breath-by-breath using a cardiopulmonary gas exchange system (Oxycon Alpha; Mijnhrdt, The Netherlands). The VT was determined by the standards of Wasserman et al. [12] and Davis et al. [13], and the V-slope method of Beaver et al. [14] from $\dot{V} \mathrm{O}_{2}, \dot{V} \mathrm{CO}_{2}$, and minute ventilation (VE).

\section{Medications}

The data on medications were obtained at interviews conducted by well-trained staff using a structured method. The subjects were asked if they were currently taking medications, i.e., those for diabetes, hypertension, dyslipidemia, and/or orthopedic diseases. When the answer was "yes", they were classified as subjects with medications. When the answer was "no", they were classified as subjects without medications.
Statistical analysis

Data are expressed as means \pm standard deviation (SD) values. There were sufficient numbers of subjects, except for subjects in their 70s without medications in the second analysis. A comparison of parameters between subjects in their 60s and those in their 70s, between subjects with and without medications, and between subjects in their 60s and those in their 70s without medications was made using an unpaired $t$-test: $p<0.05$ was considered to be statistically significant.

\section{Results}

Clinical profiles of the subjects in the first and second analyses are summarized in Tables 1 and 2. Two hundred and twenty-nine men (30.6\%) and 540 women $(39.8 \%)$ in the first analysis and 33 men (10.9\%) and 55 women $(20.6 \%)$ in the second analysis were not taking medications.

We compared the clinical parameters between subjects in their 60s and those in their 70s (Table 3). In men, height, body weight, BMI, and hip circumference in those in their 60s were significantly higher than the values in men in their 70s. However, abdominal circumference in men in their 60s was similar to that in men in their 70s. Muscle strength, flexibility, oxygen uptake at VT, work rate at VT, and heart rate at VT in men in their 60s were higher than the values in men in their 70s. In women, height was significantly 
Table 3 Changes in anthropometric and physical fitness parameters in the first and second analyses in all subjects

\begin{tabular}{|c|c|c|c|c|c|c|}
\hline & \multicolumn{3}{|l|}{ Men } & \multicolumn{3}{|l|}{ Women } \\
\hline & $60-69$ & $70-79$ & $p$ & $60-69$ & $70-79$ & $p$ \\
\hline \multicolumn{7}{|l|}{ First analysis } \\
\hline Number of subjects & 604 & 145 & & 1,158 & 199 & \\
\hline Height $(\mathrm{cm})$ & $164.8 \pm 5.3$ & $162.7 \pm 5.9$ & $<0.0001$ & $152.2 \pm 4.9$ & $149.9 \pm 4.9$ & $<0.0001$ \\
\hline Body weight (kg) & $66.5 \pm 9.0$ & $63.3 \pm 9.9$ & 0.0002 & $55.3 \pm 7.8$ & $54.8 \pm 7.9$ & 0.3793 \\
\hline Body mass index $\left(\mathrm{kg} / \mathrm{m}^{2}\right)$ & $24.5 \pm 3.0$ & $23.9 \pm 3.0$ & 0.0313 & $23.9 \pm 3.2$ & $24.4 \pm 3.3$ & 0.0373 \\
\hline Abdominal circumference $(\mathrm{cm})$ & $86.2 \pm 9.1$ & $85.6 \pm 9.5$ & 0.4998 & $78.3 \pm 9.1$ & $81.9 \pm 10.2$ & $<0.0001$ \\
\hline Hip circumference $(\mathrm{cm})$ & $92.2 \pm 5.4$ & $90.7 \pm 5.6$ & 0.0030 & $90.3 \pm 5.4$ & $90.0 \pm 5.4$ & 0.5006 \\
\hline Right grip strength (kg) & $37.3 \pm 6.8$ & $32.6 \pm 6.9$ & $<0.0001$ & $22.5 \pm 4.5$ & $20.9 \pm 4.4$ & $<0.0001$ \\
\hline Left grip strength $(\mathrm{kg})$ & $36.0 \pm 6.6$ & $30.8 \pm 6.5$ & $<0.0001$ & $21.6 \pm 4.4$ & $20.0 \pm 4.3$ & $<0.0001$ \\
\hline Leg strength $(\mathrm{kg})$ & $53.2 \pm 12.9$ & $41.9 \pm 11.3$ & $<0.0001$ & $35.9 \pm 8.5$ & $31.8 \pm 8.7$ & $<0.0001$ \\
\hline Leg strength per body weight & $0.81 \pm 0.19$ & $0.67 \pm 0.19$ & $<0.0001$ & $0.66 \pm 0.16$ & $0.59 \pm 0.17$ & $<0.0001$ \\
\hline Flexibility $(\mathrm{cm})$ & $1.0 \pm 9.9$ & $-1.1 \pm 11.3$ & 0.0278 & $11.4 \pm 8.0$ & $10.7 \pm 8.4$ & 0.3205 \\
\hline \multicolumn{7}{|l|}{ Second analysis } \\
\hline Number of subjects & 255 & 47 & & 228 & 39 & \\
\hline Oxygen uptake at VT $(\mathrm{ml} / \mathrm{kg} / \mathrm{min})$ & $12.7 \pm 1.9$ & $11.5 \pm 1.7$ & $<0.0001$ & $12.0 \pm 1.7$ & $11.1 \pm 1.5$ & 0.0024 \\
\hline Work rate at VT (watt) & $56.0 \pm 12.6$ & $40.4 \pm 12.5$ & $<0.0001$ & $40.2 \pm 10.2$ & $29.7 \pm 8.8$ & $<0.0001$ \\
\hline Heart rate at VT (beats/min) & $96.6 \pm 12.5$ & $91.2 \pm 14.0$ & 0.0080 & $99.3 \pm 12.8$ & $96.9 \pm 12.7$ & 0.2747 \\
\hline
\end{tabular}

Values are means \pm SD. $p$ values in boldface are significant

$V T$ ventilatory threshold

greater, and BMI and abdominal circumference were significantly lower in those in their 60s than the values in women in their 70s. Muscle strength, oxygen uptake at VT, and work rate at VT in those in their 60s were significantly higher than the values in women in their 70s.

We further analyzed clinical parameters, comparing them between subjects with and without medications (Table 4). There were significant differences in anthropometric parameters (except for height), muscle strength, flexibility, and work rate at VT between men with and without medications. In women, there were also significant differences in body weight, BMI, abdominal circumference, and muscle strength between the two groups.

In addition, in men in their 60s, muscle strength and flexibility in subjects without medications were significantly higher than these values in subjects with medications. In women, body weight, BMI, abdominal circumference, and hip circumference were significantly lower, and grip strength and leg strength per body weight were significantly higher in subjects without medications than these values in subjects with medications (Table 4).

In men in their 70s, anthropometric parameters were significantly lower and leg strength per body weight was significantly higher in men without medications than these values in men with medications. Muscle strength in women without medications was significantly higher than that in women with medications (Table 4).
We found that there were significant differences in some parameters between subjects with and without medications. We finally compared parameters between subjects in their $60 \mathrm{~s}$ and subjects in their $70 \mathrm{~s}$ in without medications (Table 5). In men, anthropometric parameters and muscle strength in those in their 70s were significantly lower than these values in men in their 60s. In women, only abdominal circumference in those in their 70s was higher than that in women in their 60s. There were no differences in other parameters between subjects in their 60s and those in their 70 s.

\section{Discussion}

We evaluated anthropometric parameters, muscle strength, flexibility, and aerobic exercise levels in elderly Japanese. Especially in elderly subjects without medications, this mean value for those in their $60 \mathrm{~s}$ and 70 s may provide a useful database for evaluating anthropometric parameters and physical fitness.

It has been well reported that there is significant loss in muscle strength with aging $[15,16]$. Aging is associated with alterations in body composition; there is an increase in body fat percentage and a concomitant decline in lean body mass [17]. Aging, therefore, results in substantial alterations in body composition, with a marked reduction in 
Table 4 Comparison of anthropometric and physical fitness parameters between subjects with and without medications as classified by age groups

\begin{tabular}{|c|c|c|c|c|c|}
\hline Men & & & Women & & \\
\hline Medication (-) & Medication (+) & $p$ & Medication (-) & Medication $(+)$ & $p$ \\
\hline
\end{tabular}

All subjects

First analysis

Number of subjects

Height $(\mathrm{cm})$

Body weight $(\mathrm{kg})$

Body mass index $\left(\mathrm{kg} / \mathrm{m}^{2}\right)$

Abdominal circumference $(\mathrm{cm})$

Hip circumference $(\mathrm{cm})$

Right grip strength (kg)

Left grip strength $(\mathrm{kg})$

Leg strength $(\mathrm{kg})$

Leg strength per body weight

Flexibility $(\mathrm{cm})$

Second analysis

Number of subjects

Oxygen uptake at VT $(\mathrm{ml} / \mathrm{kg} / \mathrm{min})$

Work rate at VT (watt)

Heart rate at VT (beats/min)

60-69

First analysis

Number of subjects

Height $(\mathrm{cm})$

Body weight $(\mathrm{kg})$

Body mass index $\left(\mathrm{kg} / \mathrm{m}^{2}\right)$

Abdominal circumference $(\mathrm{cm})$

Hip circumference $(\mathrm{cm})$

Right grip strength $(\mathrm{kg})$

Left grip strength $(\mathrm{kg})$

Leg strength $(\mathrm{kg})$

Leg strength per body weight

Flexibility $(\mathrm{cm})$

Second analysis

Number of subjects

Oxygen uptake at VT $(\mathrm{ml} / \mathrm{kg} / \mathrm{min})$

Work rate at VT (watt)

Heart rate at VT (beats/min)

$70-79$

First analysis

Number of subjects

Height $(\mathrm{cm})$

Body weight $(\mathrm{kg})$

Body mass index $\left(\mathrm{kg} / \mathrm{m}^{2}\right)$

Abdominal circumference $(\mathrm{cm})$

Hip circumference $(\mathrm{cm})$

Right grip strength $(\mathrm{kg})$

Left grip strength $(\mathrm{kg})$
229

\begin{tabular}{|c|c|}
\hline $64.2 \pm 5.4$ & $164.5 \pm 5.5$ \\
\hline $64.6 \pm 8.7$ & $66.5 \pm 9.5$ \\
\hline $23.9 \pm 2.7$ & $24.5 \pm 3.1$ \\
\hline $84.7 \pm 9.0$ & $86.7 \pm 9.2$ \\
\hline $91.3 \pm 5.0$ & $92.2 \pm 5.6$ \\
\hline $37.5 \pm 6.6$ & $35.9 \pm 7.2$ \\
\hline $35.8 \pm 6.7$ & $34.6 \pm 7.0$ \\
\hline $53.1 \pm 12.8$ & $50.2 \pm 13.5$ \\
\hline $0.83 \pm 0.19$ & $0.76 \pm 0.19$ \\
\hline $2.3 \pm 10.8$ & $-0.2 \pm 9.9$ \\
\hline
\end{tabular}

\section{3}

$12.9 \pm 1.8$

$59.0 \pm 12.8$

$96.7 \pm 9.9$

195

$164.8 \pm 5.0$

$65.7 \pm 8.2$

$24.2 \pm 2.6$

$85.4 \pm 8.8$

$91.8 \pm 4.7$

$38.2 \pm 6.2$

$36.8 \pm 6.3$

$54.7 \pm 12.4$

$0.84 \pm 0.19$

$2.5 \pm 10.5$

\section{0}

$12.9 \pm 1.8$

$59.5 \pm 12.5$

$97.1 \pm 10.2$

34

$160.7 \pm 6.3$

$58.2 \pm 8.8$

$22.5 \pm 3.0$

$80.5 \pm 9.4$

$88.2 \pm 5.9$

$33.4 \pm 7.4$

$30.6 \pm 6.5$

\section{9}

$12.4 \pm 2.0$

$52.9 \pm 13.8$

$95.6 \pm 13.2$

409

$164.8 \pm 5.5$

$66.9 \pm 9.4$

$24.6 \pm 3.1$

$86.6 \pm 9.2$

$92.4 \pm 5.7$

$36.8 \pm 7.0$

$35.6 \pm 6.7$

$52.5 \pm 13.1$

$0.79 \pm 0.19$

$0.2 \pm 9.6$

225

$12.7 \pm 1.9$

$55.6 \pm 12.6$

$96.5 \pm 12.8$

111

$163.3 \pm 5.7$

$64.9 \pm 9.7$

$24.3 \pm 2.9$

$87.2 \pm 9.0$

$91.5 \pm 5.3$

$32.3 \pm 6.8$

$30.9 \pm 6.6$
540

$\begin{array}{rr}0.4997 & 152.0 \pm 5.2 \\ \mathbf{0 . 0 0 9 7} & 54.4 \pm 7.6 \\ \mathbf{0 . 0 0 7 6} & 23.6 \pm 3.1 \\ \mathbf{0 . 0 0 5 5} & 77.4 \pm 9.0 \\ \mathbf{0 . 0 3 0 5} & 89.9 \pm 5.2 \\ \mathbf{0 . 0 0 2 8} & 23.0 \pm 4.4 \\ \mathbf{0 . 0 2 1 3} & 22.0 \pm 4.2 \\ \mathbf{0 . 0 0 5 9} & 36.2 \pm 8.0 \\ <\mathbf{0 . 0 0 0 1} & 0.67 \pm 0.15 \\ \mathbf{0 . 0 0 2 3} & 11.7 \pm 8.0\end{array}$

55

0.2280

0.0176

0.6505
817

$$
\begin{aligned}
151.8 & \pm 4.9 \\
55.8 & \pm 8.0 \\
24.2 & \pm 3.3 \\
79.8 & \pm 9.4 \\
90.5 & \pm 5.5 \\
21.8 & \pm 4.6 \\
21.0 & \pm 4.6 \\
34.7 & \pm 9.0 \\
0.63 & \pm 0.17 \\
11.0 & \pm 8.1
\end{aligned}
$$

0.3762

0.0015

0.0002

$<0.0001$

0.0646

$<0.0001$

$<0.0001$

0.0013

$<0.0001$

0.1189

212

$\begin{array}{ll}11.9 \pm 1.7 & 0.7549 \\ 38.2 \pm 10.8 & 0.1651 \\ 98.8 \pm 12.8 & 0.6563\end{array}$

490

0.9816

$152.2 \pm 5.1$

0.1204

$54.5 \pm 7.6$

0.0755

0.1416

$23.5 \pm 3.1$

0.1956

$77.2 \pm 8.8$

0.0168

$89.9 \pm 5.2$

0.0427

$23.1 \pm 4.5$

0.0472

$22.0 \pm 4.3$

0.0028

$36.3 \pm 8.0$

$0.67 \pm 0.15$

0.0087

$11.6 \pm 8.0$

0.5373

53

$11.8 \pm 1.7$
$40.5 \pm 9.4$
$99.6 \pm 12.6$

$0.8199 \quad 99.6 \pm 12.6$

50

0.0243

$150.4 \pm 5.5$

0.0005

$53.8 \pm 7.4$

0.0025

\begin{tabular}{|c|c|}
\hline $152.2 \pm 4.8$ & 0.8692 \\
\hline $56.0 \pm 7.9$ & 0.0016 \\
\hline $24.1 \pm 3.3$ & 0.0010 \\
\hline $79.2 \pm 9.2$ & 0.0002 \\
\hline $90.6 \pm 5.5$ & 0.0304 \\
\hline $22.1 \pm 4.5$ & 0.0006 \\
\hline $21.3 \pm 4.5$ & 0.0117 \\
\hline $35.5 \pm 8.9$ & 0.1073 \\
\hline $0.64 \pm 0.17$ & 0.0018 \\
\hline $11.1 \pm 8.0$ & 0.300 \\
\hline
\end{tabular}

$23.9 \pm 3.5$

0.0003

$80.0 \pm 10.9$

0.0029

$90.2 \pm 4.7$

0.3916

$22.7 \pm 4.0$

0.8323
668

175

$\begin{array}{ll}12.1 \pm 1.7 & 0.3367 \\ 40.1 \pm 10.2 & 0.7872 \\ 99.3 \pm 12.8 & 0.8459\end{array}$

149

$149.7 \pm 4.7 \quad 0.4049$

$55.1 \pm 8.1 \quad 0.3041$

$24.6 \pm 3.2 \quad 0.1770$

$82.6 \pm 9.9 \quad 0.1158$

$90.0 \pm 5.6 \quad 0.7944$

$20.3 \pm 4.4 \quad \mathbf{0 . 0 0 0 6}$

$19.4 \pm 4.3 \quad \mathbf{0 . 0 0 0 4}$ 
Table 4 continued

\begin{tabular}{|c|c|c|c|c|c|c|}
\hline & \multicolumn{3}{|l|}{ Men } & \multicolumn{3}{|l|}{ Women } \\
\hline & Medication (-) & Medication (+) & $p$ & Medication (-) & Medication (+) & $p$ \\
\hline Leg strength $(\mathrm{kg})$ & $43.5 \pm 11.3$ & $41.5 \pm 11.4$ & 0.3593 & $34.8 \pm 8.1$ & $30.8 \pm 8.6$ & 0.0043 \\
\hline Leg strength per body weight & $0.76 \pm 0.21$ & $0.65 \pm 0.17$ & 0.0015 & $0.65 \pm 0.16$ & $0.57 \pm 0.16$ & 0.0010 \\
\hline Flexibility (cm) & $1.0 \pm 12.4$ & $-1.8 \pm 11.0$ & 0.2127 & $12.1 \pm 8.0$ & $10.3 \pm 8.6$ & 0.1793 \\
\hline \multicolumn{7}{|l|}{ Second analysis } \\
\hline Number of subjects & 3 & 44 & & 2 & 37 & \\
\hline Oxygen uptake at VT $(\mathrm{ml} / \mathrm{kg} / \mathrm{min})$ & $12.8 \pm 1.8$ & $11.4 \pm 1.7$ & 0.1685 & $11.9 \pm 1.0$ & $11.1 \pm 1.5$ & 0.4774 \\
\hline Work rate at VT (watt) & $53.3 \pm 17.6$ & $39.5 \pm 11.9$ & 0.0642 & $37.5 \pm 3.5$ & $29.2 \pm 8.8$ & 0.1980 \\
\hline Heart rate at VT (beats/min) & $93.0 \pm 7.2$ & $91.0 \pm 14.4$ & 0.8183 & $100.5 \pm 13.4$ & $96.7 \pm 12.8$ & 0.6887 \\
\hline
\end{tabular}

Values are means \pm SD. $p$ values in boldface are significant

$V T$ ventilatory threshold

Table 5 Changes in anthropometric and physical fitness parameters in the first and second analyses in subjects without medications

\begin{tabular}{|c|c|c|c|c|c|c|}
\hline & \multicolumn{3}{|l|}{ Men } & \multicolumn{3}{|l|}{ Women } \\
\hline & $60-69$ & $70-79$ & $p$ & $60-69$ & $70-79$ & $p$ \\
\hline \multicolumn{7}{|l|}{ First analysis } \\
\hline Number of subjects & 195 & 34 & & 490 & 50 & \\
\hline Height $(\mathrm{cm})$ & $164.8 \pm 5.0$ & $160.7 \pm 6.3$ & $<0.0001$ & $152.2 \pm 5.1$ & $150.4 \pm 5.5$ & 0.0189 \\
\hline Body weight (kg) & $65.7 \pm 8.2$ & $58.2 \pm 8.8$ & $<0.0001$ & $54.5 \pm 7.6$ & $53.8 \pm 7.4$ & 0.5481 \\
\hline Body mass index $\left(\mathrm{kg} / \mathrm{m}^{2}\right)$ & $24.2 \pm 2.6$ & $22.5 \pm 3.0$ & 0.0012 & $23.5 \pm 3.1$ & $23.9 \pm 3.5$ & 0.4736 \\
\hline Abdominal circumference $(\mathrm{cm})$ & $85.4 \pm 8.8$ & $80.5 \pm 9.4$ & 0.0035 & $77.2 \pm 8.8$ & $80.0 \pm 10.9$ & $\mathbf{0 . 0 3 8 3}$ \\
\hline Hip circumference $(\mathrm{cm})$ & $91.8 \pm 4.7$ & $88.2 \pm 5.9$ & 0.0001 & $89.9 \pm 5.2$ & $90.2 \pm 4.7$ & 0.7027 \\
\hline Right grip strength kg) & $38.2 \pm 6.2$ & $33.4 \pm 7.4$ & $<0.0001$ & $23.1 \pm 4.5$ & $22.7 \pm 4.0$ & 0.5974 \\
\hline Left grip strength (kg) & $36.8 \pm 6.3$ & $30.6 \pm 6.5$ & $<0.0001$ & $22.0 \pm 4.3$ & $21.9 \pm 3.9$ & 0.8747 \\
\hline Leg strength $(\mathrm{kg})$ & $54.7 \pm 12.4$ & $43.5 \pm 11.3$ & $<0.0001$ & $36.3 \pm 8.0$ & $34.8 \pm 8.1$ & 0.1953 \\
\hline Leg strength per body weight & $0.84 \pm 0.19$ & $0.76 \pm 0.21$ & 0.0250 & $0.67 \pm 0.15$ & $0.65 \pm 0.16$ & 0.3706 \\
\hline Flexibility (cm) & $2.5 \pm 10.5$ & $1.0 \pm 12.4$ & 0.4562 & $11.6 \pm 8.0$ & $12.1 \pm 8.0$ & 0.6805 \\
\hline \multicolumn{7}{|l|}{ Second analysis } \\
\hline Number of subjects & 30 & 3 & & 53 & 2 & \\
\hline Oxygen uptake at VT $(\mathrm{ml} / \mathrm{kg} / \mathrm{min})$ & $12.9 \pm 1.8$ & $12.8 \pm 1.8$ & 0.9404 & $11.8 \pm 1.6$ & $11.9 \pm 1.0$ & 0.9520 \\
\hline Work rate at VT (watt) & $59.5 \pm 12.5$ & $53.3 \pm 17.6$ & 0.4342 & $40.5 \pm 9.4$ & $37.5 \pm 3.5$ & 0.6526 \\
\hline Heart rate at VT (beats/min) & $97.1 \pm 10.2$ & $93.0 \pm 7.2$ & 0.5071 & $99.6 \pm 12.6$ & $100.5 \pm 13.4$ & 0.9253 \\
\hline
\end{tabular}

Values are means \pm SD. $p$ values in boldface are significant

$V T$ ventilatory threshold

skeletal muscle mass. It has also been well reported that there is significant loss in oxygen uptake at the ventilatory threshold (VT) -which is also considered an accurate and reliable parameter of aerobic exercise level [13]-with aging $[18,19]$. Miura reported that oxygen uptake at VT was significantly correlated with age (men, $r=-0.626$; women, $r=-0.578$ ) in 610 Japanese [18]. Sanada et al. reported that a negative correlation was noted between oxygen uptake at VT and age in 1,463 Japanese [19]. However, there are few reports of the evaluation of physical fitness in elderly Japanese. In the previous studies noted above, the number of subjects over the age of 70 was 20 in men and 16 in women [18], and 65 in men and 13 in women [19]. Especially, there are no accurate reference data for physical fitness in Japanese subjects over the age of 70 without medications. We have previously reported on changes in maximal oxygen uptake in subjects aged 20-69 years [20]. In the present study, we evaluated anthropometric parameters, muscle strength, flexibility, and aerobic exercise levels in subjects over the age of 60 . We measured anthropometric parameters, muscle strength, and flexibility in 145 men and 199 women in their 70s. 
In addition, we compared parameters between subjects with and without medications. Although we evaluated VT in only 3 men and 2 women in their 70s without medications, this information gathered should serve as quite a useful database for evaluating anthropometric parameters, muscle strength, flexibility, and aerobic exercise levels in elderly Japanese subjects.

We found a difference in anthropometric parameters and muscle strength between men with and without medications in their 60s and 70s. However, in women, abdominal circumference in those in their 70s was higher than that in women in their $60 \mathrm{~s}$, while other parameters in women in their 70s were similar to values in those in their 60s. Sanada et al. [19] also reported that, in women, fat-free body mass in those in their $70 \mathrm{~s}(41.5 \pm 3.5 \mathrm{~kg})$ was similar to that in women in their $60 \mathrm{~s}(40.0 \pm 4.4 \mathrm{~kg})$, while in men, fat-free mass in those in their $70 \mathrm{~s}(52.9 \pm 4.1 \mathrm{~kg})$ was lower than that in men in their $60 \mathrm{~s}(55.3 \pm 52.9 \mathrm{~kg})$. Previous exercise habits, current exercise habits, and sample size may affect the results.

There are potential limitations in the present study. First, our study was a cross-sectional and not a longitudinal study. Second, the 2,106 elderly subjects, all of whom wanted to change their lifestyle, underwent measurements for this study: they were therefore more health-conscious than the average person. The 569 subjects selected in the second analysis underwent aerobic exercise testing; they were therefore more health-conscious than most of the subjects in the first analysis. Third, the small sample size, especially of subjects in their 70s without medications, might make it difficult to compare aerobic exercise levels between subjects with and without medications, and to compare these levels between subjects in their 60s and those in their 70s. In addition, the death rate in subjects aged 75-79 is higher than that in those aged 70-74 [21]. Therefore, it is well expected that there are differences in physical fitness between subjects aged 70-74 and those aged 75-79. Further large-sample-size and prospective studies are needed in elderly Japanese.

Acknowledgments This research was supported in part by Research Grants from the Ministry of Health, Labor, and Welfare, Japan.

\section{References}

1. Health and Welfare Statistics Association. J Health Welfare Stat. 2009;56:39 (in Japanese).

2. Sjostrom LV. Mortality of severely obese subjects. Am J Clin Nutr. 1992;55(2):516S-23S.

3. Sjostrom LV. Morbidity of severely obese subjects. Am J Clin Nutr. 1992;55(2):508S-15S.
4. Pouliot MC, Despres JP, Nadeeau A, Tremblay A, Moorjani S, Lupien PJ, et al. Visceral obesity in men. Associations with glucose tolerance, plasma insulin, and lipoprotein levels. Diabetes. 1992;41:826-34.

5. Sandvik L, Erikssen J, Thaulow E, Erikssen G, Mundal R, Rodahl $\mathrm{K}$, et al. Physical fitness as a predictor of mortality among healthy, middle-aged Norwegian men. $N$ Engl $J$ Med. 1993;25:533-7.

6. Metter EJ, Talbot LA, Schrager M, Conwit R, et al. Skeletal muscle strength as a predictor of all-cause mortality in healthy men. J Gerontol A Biol Sci Med Sci. 2002;57:B359-65.

7. Definition and the diagnostic standard for metabolic syndromeCommittee to Evaluate Diagnostic Standards for Metabolic Syndrome. Nippon Naika Gakkai Zasshi. 2005;94:794-809 (in Japanese).

8. Kigawa A, Yamamoto T, Koyama Y, Kageyama S, Arima K. Evaluation of knee extensor strength for prevention of sports injury. Japan Orthop Soc Sports Med. 1987;6:141-5. (in Japanese).

9. Miyatake N, Takahashi K, Wada J, Nishikawa H, Morishita A, Suzuki H, et al. Changes in serum leptin concentrations in overweight men after exercise. Diabetes Obes Metab. 2004; 6:332-7.

10. Miyatake N, Nishikawa H, Fujii M, et al. Clinical evaluation of physical fitness in male obese Japanese. Chin Med J (Engl). 2001;114:707-10.

11. Jones NL, Makrides L, Hitchcock C, Chypchar T, McCartney N, et al. Normal standards for an incremental progressive cycle ergometer test. Am Rev Respir Dis. 1985;131:700-8.

12. Wasserman K, Whipp BJ, Koyl SN, Beaver WL, et al. Anaerobic threshold and respiratory gas exchange during exercise. J Appl Physiol. 1973;35:236-43.

13. Davis JA, Frank MH, Whipp BJ, Wasserman K, et al. Anaerobic threshold alterations caused by endurance training in middle-aged men. J Appl Physiol. 1979;46:1039-46.

14. Beaver WL, Wasserman K, Whipp BJ, et al. A new method for detecting anaerobic threshold by gas exchange. J Appl Physiol. 1986;60:2020-7.

15. Larsson L, Karlsson J, et al. Isometric and dynamic endurance as a function of age and skeletal muscle characteristics. Acta Physiol Scand. 1978;104:129-36.

16. Young A, Stokes M, Crowe M, et al. Size and strength of the quadriceps muscles of old and young women. Eur J Clin Invest. 1984;14:282-7.

17. Rogers MA, Evans WJ, et al. Changes in skeletal muscle with aging: effects of exercise training. Exerc Sports Sci Rev. 1993;21:65-102.

18. Miura K. Ventilatory threshold in Japanese-as the basis for exercise prescription for health promotion. Nippon Koshu Eisei Zasshi. 1996;43:220-30. (in Japanese).

19. Sanada K, Kuchiki T, Miyachi M, McGrath K, Higuchi M, Ebashi $\mathrm{H}$, et al. Effect of age on ventilatory threshold and peak oxygen uptake normalized for regional skeletal mass in Japanese men and women aged 20-80 years. Eur J Appl Physiol. 2006;99:475-83.

20. Miyatake N, Miyachi M, Tabata I, Numata T, et al. Body fat percentage measured by dual energy $\mathrm{X}$-ray absorptiometry is associated with maximal oxygen uptake at in Japanese. Anti Aging Med. 2009;6:41-5.

21. Ministry of Health, Labor and Welfare, Japan. (Cited April 18, 2011). http://www.mhlw.go.jp/toukei/saikin/hw/jinkou/geppo/ nengai08/kekka3.html. 